possible that it does improve in some way, not appreciable objectively, the internal nutrition of the eye structures. Peritomy I used to do often, but it never had any good effect. Optical iridectomies in this condition are practically never successful, and I have tried them frequently. There seems to be so much post-operative lymphexudation following for one thing. Finally, trachoma is a disease which exists only as the result of the absence of the most elementary personal hygiene. If this is present there is no danger of the spread of the infection, and a certainty of its ultimate disappearance from the face of the globe.

\title{
THE MEDICO-LEGAL INTEREST OF A CASE OF BINOCULAR KERATITIS FOLLOWING UNIOCULAR IN JURY*
}

BY

\author{
R. J. Coulter, D.O.Oxon.
}

OPHTHALMIC SURGEON TO THE ROYAL GWENT HOSPITAL, NEWPORT, MON.

CASES of uniocular keratitis following injury have been reported by various observers, but instances in which the second eye has become affected are not so common. In the literature at my disposal I have only been able to find records of such a condition by Ohm, Asmus, and H. Work Dodd (three cases). Owing to the medico-legal interest of the subject I venture to bring the following case to the notice of the Congress :-

H. D. J., marine engineer, aged 25, of good family and personal history, was struck on the outside of the left eye by a piece of steel on November 2, 1915. He reported the accident to the second engineer, but nothing was found in the eye. He was treated by the captain until he reached Savona six days later, where he was treated by an Italian oculist, who said he would try to keep the right eye safe and that it had either come on from disease or from a blow on the eye. He went with his ship to Baltimore, U.S.A.- where he was again under the care of an ophthalmic surgeon-St. John, New Brunswick, Plymouth, Calais, and Cardift, where he was discharged. He came to my out-patient department at the Royal Gwent Hospital on March 6, 1916, when I found the right eye healthy and opacities in the left cornea evidently the result of keratitis. His vision then was right eye $6 / 18-3.5 \mathrm{D}$. cyl. axis $15^{\circ} 6 / 9$; left eye $6 / 36-0.75 \mathrm{D}$. sph. $-5 \mathrm{D}$. cyl. axis $165^{\circ} 6 / 36$. There was a deep-seated central cloud in the cornea with residual vessels in the left eye. The right eye was healthy.

\footnotetext{
* A communication to the Oxford Ophthalmological Congress, July, 1917.
} 
On May 4, 1916, he went as third engineer on the s.s. Falcon. His eyes were good except that there was a mist over the left until May 20, when the right suddenly became inflamed. On his return home he was sent to me for examination by his employers on June 2, 1916, when I found a keratitis resembling interstitial keratitis in his right eye, the vision of which was reduced to counting fingers at half a metre. He has been under my care since then, and the case has run the ordinary course of a mild interstitial keratitis. The eye is now free from inflammation, but there is still a central corneal opacity with some deep vessels. Its vision is only 1/60. The condition of the left eye is unaltered. The Wassermann reaction is negative. There is no clinical evidence of syphilis or tuberculosis.

In December, 1916, the man brought an action for compensation in the Newport County Court, and was awarded $£ 1$ per week.

The first question which arises in discussing this case is whether there ever was an injury. In the absence of early medical examination this must depend largely on the man's own statement; but the fact that he reported it to the second engineer, and that his employers had to admit it in a court of law, tend to corroborate his story.

The next question is whether the accident caused the keratitis in the left eye or was merely a coincidence; but in view of the fact that such a sequence is not uncommon, it seems that the injury probably started the inflammation.

When we come to consider the connection between the accident and the inflammation in the second eye, we are faced by a more difficult question. If the injury merely started an inflammation in the first eye, which would in any case have broken out sooner or later, it is difficult to see how it can be regarded as causal for the second eye. On the other hand, if it gave rise to an inflammation which would otherwise not have occurred, and this in turn spread to the second eye, this suggests that in ordinary non-traumatic interstitial keratitis the inflammation in the first eye may cause, as well as precede, the trouble in the second eye, and that there are analogies between interstitial keratitis and sympathetic inflammation which may be worth study.

\section{REFERENCES}

I. Ohm.-Woch. f. Ther, u. Hyg. d. Aug., No. 5, 1905.

2. Asmus -Zeitschr.f. Aug., I909, Vol. XXII, p. 335.

3. Dodd, H. Work. - Ophthalmoscope, Vol. II (I904), p. I76. 